\title{
Response of Acanthamoeba castellanii mitochondria to oxidative stress
}

\author{
Lidia K. Trocha ${ }^{1 \bowtie}$ and Olgierd Stobienia ${ }^{2}$ \\ ${ }^{1}$ Institute of Dendrology, Polish Academy of Sciences, Kórnik, Poland; ${ }^{2}$ Adam Mickiewicz University, Institute \\ of Molecular Biology and Biotechnology, Department of Bioenergetics, Poznań, Poland
}

Received: 22 August, 2007; revised: 14 November, 2007; 03 December, 2007

available on-line: 13 December, 2007

\begin{abstract}
The purpose of this study was to examine the effects of oxidative stress caused by hydroperoxide $\left(\mathrm{H}_{2} \mathrm{O}_{2}\right)$ in the presence of iron ions $\left(\mathrm{Fe}^{2+}\right)$ on mitochondria of the amoeba Acanthamoeba castellanii. We used isolated mitochondria of $A$. castellanii and exposed them to four levels of $\mathrm{H}_{2} \mathrm{O}_{2}$ concentration: $0.5,5,15$, and $25 \mathrm{mM}$. We measured basic energetics of mitochondria: oxygen consumption in phosphorylation state (state 3 ) and resting state (state 4), respiratory coefficient rates (RC), ADP/O ratios, membrane potential $\left(\Delta \Psi_{\mathrm{m}}\right)$, ability to accumulate $\mathrm{Ca}^{2+}$, and cytochrome $c$ release. Our results show that the increasing concentrations of $\mathrm{H}_{2} \mathrm{O}_{2}$ stimulates respiration in states 3 and 4 . The highest concentration of $\mathrm{H}_{2} \mathrm{O}_{2}$ caused a 3-fold increase in respiration in state 3 compared to the control. Respiratory coefficients and ADP/O ratios decreased with increasing stress conditions. Membrane potential significantly collapsed with increasing hydroperoxide concentration. The ability to accumulate $\mathrm{Ca}^{2+}$ also decreased with the increasing stress treatment. The lowest stress treatment $\left(0.5 \mathrm{mM} \mathrm{H} \mathrm{O}_{2}\right)$ significantly decreased oxygen consumption in state 3 and 4 , $\mathrm{RC}$, and membrane potential. The ADP/O ratio decreased significantly under $5 \mathrm{mM} \mathrm{H}_{2} \mathrm{O}_{2}$ treatment, while $\mathrm{Ca}^{2+}$ accumulation rate decreased significantly at $15 \mathrm{mM} \mathrm{H}_{2} \mathrm{O}_{2}$. We also observed cytochrome $c$ release under increasing stress conditions. However, this release was not linear. These results indicate that as low as $0.5 \mathrm{mM} \mathrm{H}_{2} \mathrm{O}_{2}$ with $\mathrm{Fe}^{2+}$ damage the basic energetics of mitochondria of the unicellular eukaryotic organism Acanthamoeba castellanii.
\end{abstract}

Keywords: Acanthamoeba castellanii, mitochondria, hydroperoxide, oxidative stress

\section{INTRODUCTION}

Living cells produce non-destructive levels of reactive oxygen species (ROS) such as superoxide $\left(\mathrm{O}_{2}{ }^{--}\right)$and hydrogen peroxide $\left(\mathrm{H}_{2} \mathrm{O}_{2}\right)$ via the respiratory chain in mitochondria (Fleury et al., 2002; Chen et al., 2003; Czarna \& Jarmuszkiewicz, 2005) and during enzymatic reactions involving oxidoreductases and NAD(P)H (Li \& Trush, 1998).

There are many different exogenic inducers of ROS, such as: UV irradiance and relatively high concentrations of copper $\left(\mathrm{Cu}^{+}\right)$or iron $\left(\mathrm{Fe}^{2+}\right)$ ions in the cell. $\mathrm{Fe}^{2+}$ reacts with $\mathrm{H}_{2} \mathrm{O}_{2}$ in the Fenton reaction inducing a rise in hydroxyl radical $\left({ }^{\circ} \mathrm{OH}\right)$ molecules, which is a very reactive oxygen species (Minotti \&
Aust, 1987; Fleury et al., 2002). The excess of ROS or lack of cell antioxidants (catalases, dismutases, peroxidases, glutathione etc.) contributes to an oxidative stress occurrence, which in turn leads to damage of mitochondrial DNA, proteins, and membranes, accelerates ageing, and in many cases leads to cell death (Papa \& Skulachev, 1997).

In the present work we used mitochondria of the non-photosynthetic soil protozoan Acanthamoeba castellanii (Protista), which combines some features of mammalian, fungal and plant mitochondria. The occurrence of respiratory chain is a mammalian, fungal and plant characteristic, whereas the alternative oxidase (AOX) occurs in plants and some primitive fungi (Jarmuszkiewicz et al., 1997). This

\footnotetext{
${ }^{\square}$ Corresponding author: Lidia K. Trocha, Institute of Dendrology, Polish Academy of Sciences, Parkowa 5, 62-035 Kórnik, Poland; fax: (48) 61817 0166; tel.: (48) 61817 0033; e-mail: lidiatrocha@gazeta.pl

Abbreviations: ADP/O, number of ADP molecules converted to ATP while 2 electrons are carried from substrate via respiratory chain to 1 atom of oxygen resulting in reducing it to 1 molecule of water; AOX, alternative oxidase; MA, malate; $\mathrm{RC}$, respiratory rate coefficient; ROS, reactive oxygen species; VDAC, voltage-dependent anion selective channel; $\Delta \Psi_{\mathrm{m}}{ }^{\prime}$ mitochondrial membrane potential.
} 
makes the amoeba an attractive model organism. In addition, mitochondria of $A$. castellanii are able to actively accumulate calcium ions (Domka-Popek \& Michejda, 1986). The influx of $\mathrm{Ca}^{2+}$ occurs through the outer membrane via voltage dependent anion selective channel (VDAC) and via calcium uniporter in the inner membrane (Bernardi, 1999; Gincel et al., 2001). Calcium ion accumulation leads to an increase of oxygen consumption in the resting state (state 4) and simultaneously decreases the mitochondrial membrane potential $\Delta \Psi_{\mathrm{m}}$. The active accumulation of $\mathrm{Ca}^{2+}$ requires protonmotive force generated by respiratory chain (Domka-Popek \& Michejda, 1986). Mitochondria of $A$. castellanii also contain a vast amount of catalase (Michejda et al., 1988).

Both mitochondrion swelling caused by overaccumulation of $\mathrm{Ca}^{2+}$ (Balzacq et al., 2002; Halestrap et al., 2002) and membrane lipid peroxidation caused by excess amounts of ROS trigger mitochondrial cytochrome $c$ release and set off a destructive cascade of events (Stridh et al., 1998; Shimizu et al., 1999; 2000; Martinou et al., 2000).

The objective of the present work was to examine the effect of the Fenton reaction (its substrates and product) on: $\Delta \Psi_{\mathrm{m}}$ generation, $\mathrm{Ca}^{2+}$ ion uptake and accumulation ability, oxygen consumption, and cytochrome $c$ release in mitochondria of Acanthamoeba castellanii. Little is known about the direct effect of oxidative stress on mitochondria of lower eukaryotic organisms such as the amoeba $A$. castellanii. To fill this information gap we conducted a series of experiments using increasing concentrations of $\mathrm{H}_{2} \mathrm{O}_{2}$ in the presence of $\mathrm{Fe}^{2+}$ and isolated mitochondria of Acanthamoeba castellanii.

\section{MATERIALS AND METHODS}

Cell culture. Cells of A. castellanii (Neff strain) were cultured as described earlier by Jarmuszkiewicz et al. (1997). Trophozoites of the amoeba were collected between $60-72 \mathrm{~h}$ following inoculation at the middle exponential phase (at a density of 5 to $\left.6 \times 10^{6} \mathrm{cells} / \mathrm{ml}\right)$.

Mitochondria isolation. The cells were separated from culture medium using centrifugation $(900 \times g, 2 \mathrm{~min})$. The pellet was suspended in isolation buffer $\mathrm{A}(\mathrm{pH}=7.4,0.14 \mathrm{M}$ sucrose, $10 \mathrm{mM}$ Tris/ $\mathrm{Cl}$ ) and centrifuged at $900 \times \mathrm{g}$ for $2 \mathrm{~min}$. The pellet was suspended in isolation buffer $B(p H=7.8,0.25$ M sucrose, $10 \mathrm{mM}$ Tris/ $\mathrm{Cl}, 0.5 \mathrm{mM}$ EGTA, 2\% BSA (bovine serum albumin)) and homogenized using a hand homogenizer. Homogenized cells were sieved through antiseptic gauze and centrifuged for $5 \mathrm{~min}$ at $1650 \times g$. The supernatant was centrifuged at $11250 \times g$ for $15 \mathrm{~min}$. The pellet was suspended in isolation buffer $\mathrm{C}(\mathrm{pH}=7.4,0.25 \mathrm{M}$ sucrose, $10 \mathrm{mM}$
Tris/Cl, $0.5 \mathrm{mM}$ EGTA, 0.2\% BSA) and centrifuged at $11250 \times \mathrm{g}$ for $15 \mathrm{~min}$. The pellet was suspended in incubation buffer $\mathrm{D}(\mathrm{pH}=7.4,0.25 \mathrm{M}$ sucrose, $10 \mathrm{mM}$ Tris/Cl) and centrifuged as above. Purified mitochondria were suspended in a small amount of the incubation buffer and kept on ice. The isolation procedure was performed at $0-4^{\circ} \mathrm{C}$. Mitochondrial protein concentration was determined by the biuret method using BSA as a standard.

The oxidative stress model. Oxidative stress model conditions (concentrations of $\mathrm{H}_{2} \mathrm{O}_{2}$ and incubation time) were established experimentally. Samples containing $2.5-3 \mathrm{mg}$ of mitochondrial protein were treated with $\mathrm{H}_{2} \mathrm{O}_{2}$ at final concentrations of $0.5,5,15$, and $25 \mathrm{mM}$. To trigger the Fenton reaction a small volume of $\mathrm{Fe}^{2+}\left(\mathrm{FeCl}_{2}\right.$ diluted in $50 \mathrm{mM}$ $\mathrm{NaCl}, \mathrm{pH}=7.0$ ) was added. Autoxidation of free $\mathrm{Fe}^{2+}$ at neutral $\mathrm{pH}$ and an inert medium like $\mathrm{NaCl}$ is extremely slow (Minotti \& Aust, 1987). Incubations were performed for 1 and $5 \mathrm{~min}$ (for the latter data not shown) at $0-4^{\circ} \mathrm{C}$. The reactions were stopped by 100 -fold dilution with the reaction medium and the samples were centrifuged at $10000 \times g$ at $0^{\circ} \mathrm{C}$ for 20 $\mathrm{s}$. The pellets containing stressed mitochondria were suspended gently in $100 \mu \mathrm{l}$ of the incubation buffer and then used for the measurements of oxygen consumption, membrane potential, and calcium ion uptake. Supernatants were collected and used to estimate cytochrome $c$ release.

Membrane potential. Membrane potential was monitored with a $\mathrm{TPP}^{+}$-specific electrode at room temperature. Weinbach's buffer $(\mathrm{pH}=7.4$, $120 \mathrm{mM} \mathrm{KCl}, 20 \mathrm{mM}$ Tris/Cl, $8 \mathrm{mM} \mathrm{MgCl}$, $3 \mathrm{mM}$ $\mathrm{KH}_{2} \mathrm{PO}_{4}, 0.2 \% \mathrm{BSA}$ ) was used as an incubation medium. Individual samples contained $2.5-3 \mathrm{mg}$ of mitochondrial proteins. Malate (MA) was added as the respiratory substrate $(3 \mathrm{mM})$, then $130 \mu \mathrm{M}$ ADP, and $0.1 \mu \mathrm{M}$ FCCP at the end to dissipate mitochondrial potential. The electrode was calibrated before each measurement. The membrane potential was calculated according to Kamo's equation without any correction because we were interested only in the relative changes in $\Delta \Psi_{\mathrm{m}}$.

Oxygen consumption. Mitochondrial respiration was measured polarographically at room temperature using a Clark-type electrode in $3 \mathrm{ml}$ of Weinbach's buffer containing: $3 \mathrm{mM}$ malate, $30 \mu \mathrm{M}$ $\mathrm{ADP}=90$ nmols (as pre puls), $120 \mu \mathrm{M}=360 \mathrm{nmols}$ $\mathrm{ADP}$, and $1 \mu \mathrm{M}$ FCCP, and with $2.5-3 \mathrm{mg}$ of mitochondrial protein. We calculated the respiratory control coefficient $(\mathrm{RC})$ and the $\mathrm{ADP} / \mathrm{O}$ ratio for each measurement.

Calcium ion uptake. The measurements of $\mathrm{Ca}^{2+}$ uptake and accumulation by mitochondria were carried out using a $\mathrm{TPP}^{+}$-specific electrode at room temperature for $2.5-3 \mathrm{mg}$ mitochondrial protein per individual measurement. Weinbach's 
buffer was used as medium with $3 \mathrm{mM}$ malate as the respiration substrate. After malate addition, known amounts of calcium ions (about 150 nmols/mg of mitochondrial protein) were sequentially added to the medium until the membrane potential collapsed. Kamo's equation was used to calculate the membrane potential. Calcium ion portions were added and the membrane potential and time of $\Delta \Psi_{\mathrm{m}}$ rebuilding were measured. Mitochondria disruption was assumed when no $\Delta \Psi_{\mathrm{m}}$ was observed.

Cytochrome $c$ release. Cytochrome $c$ release was assessed spectrophotometrically at $550 \mathrm{~nm}$. The measurements were monitored in quartz cuvettes containing $1 \mathrm{ml}$ of mitochondrial solution with a small amount of sodium dithionite to reduce released cytochrome $c$. We used supernatants of stressed mitochondria after centrifugation and suspension in the incubation buffer (2.5-3 mg of mitochondrial protein per reaction were used).

Statistics. For all variables, statistical differences among treatments were analyzed using analysis of variance (GLM procedures). Multiple comparisons among traits for different stress variants were conducted using Tukey's HSD test. Relationships among the studied traits were determined using correlation and regression analyses. All statistical analyses were conducted with JMP software (version 5.0.1a, SAS Institute, Cary, NC, USA).

\section{RESULTS}

\section{Respiration rates, respiration rate coefficients (RC)} and $\mathrm{ADP} / \mathrm{O}$ ratios

Our results indicate that increasing concentration of the Fenton reagent $\left(\mathrm{H}_{2} \mathrm{O}_{2}\right)$ stimulates respiration in the phosphorylation state (state 3 ) and the resting state (state 4) (Fig. 1a, b). The effects were concentration-dependent (Fig. 1 a, b). Increasing stress conditions increased respiration in state 3 $(P<0.0001)$ and state $4(P<0.0001)$. The highest concentration of $\mathrm{H}_{2} \mathrm{O}_{2}$ increased respiration about 3-fold compared with the control in state 3 (Fig. 1a), and 12.5-fold in state 4 (Fig. 1b). Based on the respiration rates in states 3 and 4 we calculated respiration rate coefficients (RC) and $\mathrm{ADP} / \mathrm{O}$ ratios for the stress and control treatments. Both $\mathrm{RC}$ and $\mathrm{ADP} / \mathrm{O}$ decreased with increasing concentration of $\mathrm{H}_{2} \mathrm{O}_{2}(P<0.0001$, Fig. 2 and Fig. 3). The highest respiration coefficient was $11.35 \pm 0.5$ for the control, whereas the lowest was $2.86 \pm 0.05$ for the $25 \mathrm{mM} \mathrm{H}_{2} \mathrm{O}_{2}$ treatment (Fig. 2). The highest ADP/O value was for the control, $2.9 \pm 0.02$, whereas the lowest was $1.13 \pm 0.01$ for the $25 \mathrm{mM}$ treatment (Fig. 3). Tukey's HSD test revealed no significant difference between the ADP/O
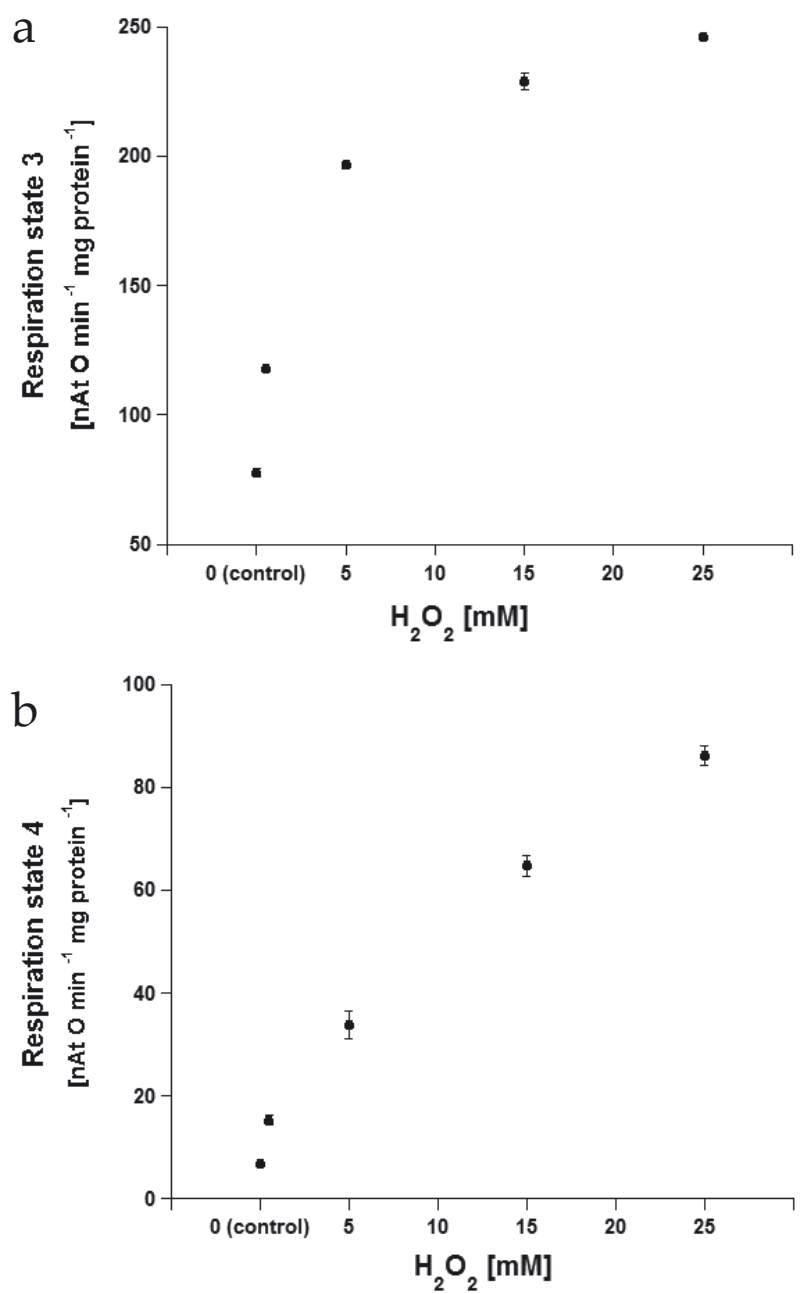

Figure 1. Respiration rates of A. castellanii mitochondria in states 3 (a) and 4 (b) for control and stress treatments. S.E. bars are shown. P-values derived from one-way ANOVA.

ratios for the control and $0.5 \mathrm{mM}$ stress treatment. However, the whole model was highly significant.

\section{Mitochondrial membrane potential $\Delta \Psi \mathrm{m}$ and active accumulation of $\mathrm{Ca}^{2+}$}

Mitochondrial membrane potential values generated after malate addition for all treatments are presented in Fig. 4. The rates gave us information about mitochondrial membrane coupling. The ability and timing of ADP transformation to ATP was calculated after addition of $360 \mathrm{nmols}$ of ADP to the reaction medium. Membrane potential rates significantly decreased with increasing stress conditions from the highest $(196.5 \pm 0.58 \mathrm{mV})$ for the control to the lowest $(159 \pm 0.82 \mathrm{mV})$ for the $25 \mathrm{mM} \mathrm{H}_{2} \mathrm{O}_{2}$ stress treatment. The whole model was highly significant $(P<0.0001)$ and all variables were significant based on Tukey's HSD test (Fig. 4). The lowest stress conditions (0.5 


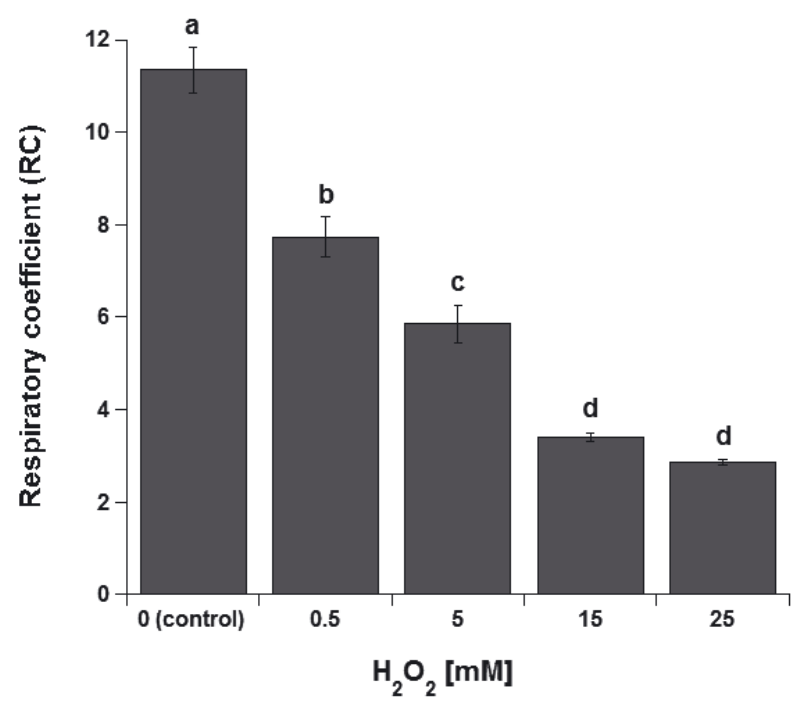

Figura 2. Respiratory coefficients (RC) of A. castellanii mitochondria for control and stress treatments $( \pm$ S.E.). For each variant, means with different letters are significantly different (Tukey's HSD test, $P=0.05)$. $P$-values are based on one-way ANOVA.

$\mathrm{mM} \mathrm{H}_{2} \mathrm{O}_{2}$ ) brought about a significant collapse of membrane potential in mitochondria of $A$. castellanii (Fig. 4). Active $\mathrm{Ca}^{2+}$ accumulation was measured as $\mu$ mols of $\mathrm{Ca}^{2+}$ added to the reaction medium containing A. castellanii mitochondria (Fig. 5). The measurements were performed as long as the mitochondrial membrane potential was collapsed. The measurements made it possible to calculate $\mathrm{Ca}^{2+}$ accumulation rates expressed as the amount of $\mathrm{Ca}^{2+}(\mu \mathrm{mols})$ accumulated during one minute per one milligram

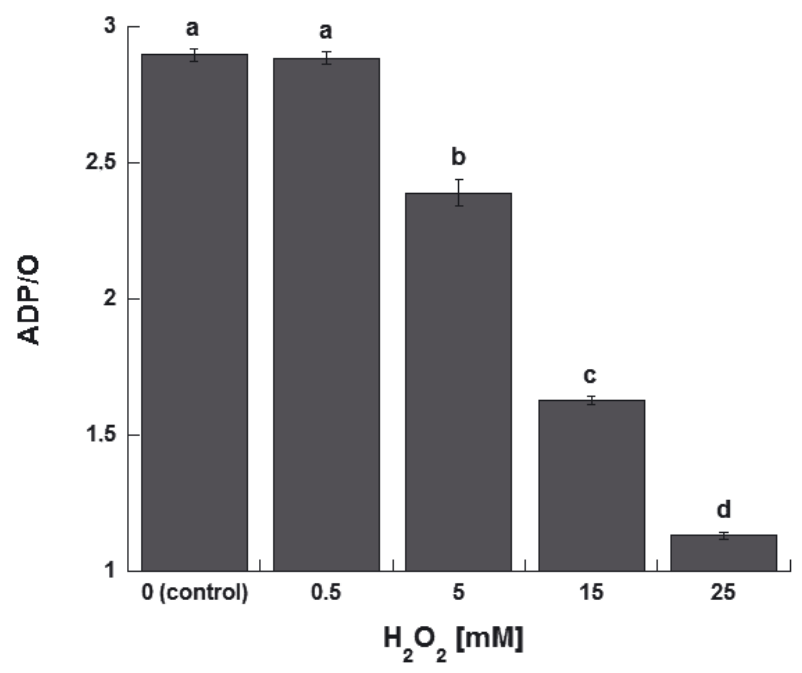

Figura 3. The ADP/O ratios of A. castellanii mitochondria for control and stress treatments $( \pm$ S.E.).

For each variant, means with different letters are significantly different (Tukey's HSD test, $P=0.05$ ). $P$-values are based on one-way ANOVA.

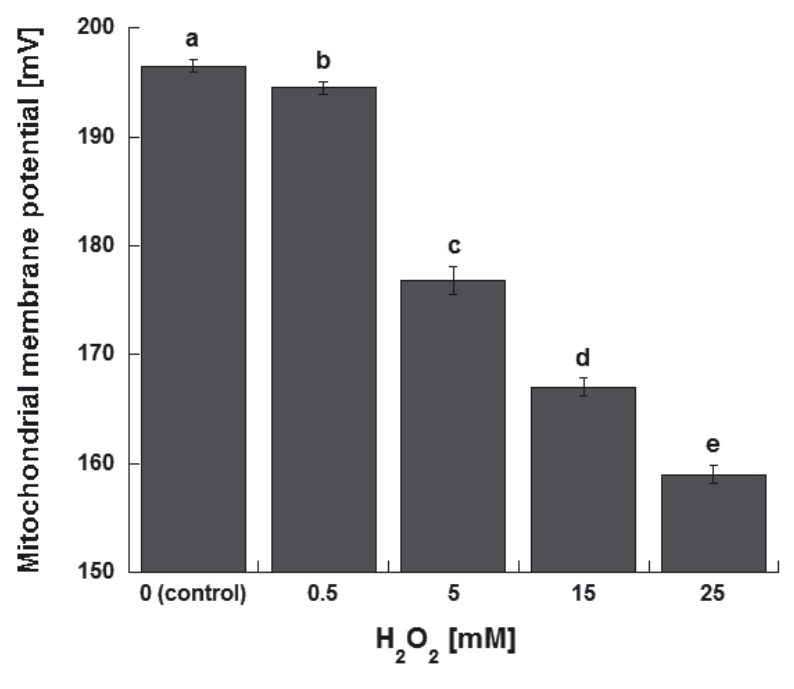

Figure 4. The mitochondrial membrane potential values of $A$. castellanii mitochondria generated after malate addition ( \pm SE).

For each variant, means with different letters are significantly different (Tukey's HSD test, $P=0.05$ ). $P$-values are based on one-way ANOVA.

of mitochondrial protein (Fig. 5). We calculated the rates for all treatments except for the highest stress condition $\left(25 \mathrm{mM} \mathrm{H}_{2} \mathrm{O}_{2}\right)$ because the time of $\Delta \Psi_{\mathrm{m}}$ depletion was under $1 \mathrm{~min}$ and longer measurement could have given us a biased rate. The accumulation of calcium ions decreased with increasing stress conditions (Fig. 5). The whole model was statistically significant $(P<0.0001)$. However, there was no significant difference between the $0.5 \mathrm{mM}$ and 5 $\mathrm{mM}$ stress treatments. Control mitochondria of $A$. castellanii accumulated on average $4.25 \mu \mathrm{mols}$ (per 2.5-3 $\mathrm{mg}$ of mitochondrial protein) before depletion, whereas mitochondria incubated in $25 \mathrm{mM} \mathrm{H}_{2} \mathrm{O}_{2}$ accumulated less than $0.5 \mu \mathrm{mol}$ of $\mathrm{Ca}^{2+}$ before depletion. The speed of accumulation of calcium ions varied among treatments (Fig. 5; $P<0.0001$ ). To obtain relevant factor reflecting the ability of $A$. castellanii mitochondria to actively accumulate $\mathrm{Ca}^{2+}$ we used $\mathrm{Ca}^{2+}$ accumulation rates (Fig. 5). The rates decreased with increasing stress conditions. The highest was $0.16 \mu \mathrm{mol} \mathrm{min}{ }^{-1} \mathrm{mg}^{-1}$ for the control and the lowest was $0.08 \mu \mathrm{mol} \mathrm{min}{ }^{-1} \mathrm{mg}^{-1}$ for the $15 \mathrm{mM}$ treatment. The whole model was highly significant: $P=0.0019$. However, there was no significant difference among control, $0.5 \mathrm{mM}$ and $5 \mathrm{mM}$ treatments based on the Tukey's HSD test.

\section{Cytochrome $c$ release}

To measure cytochrome $c$ released from the intermembrane space as a result of outer membrane peroxidation, we conducted spectrophotometrical 
total $\mathrm{Ca}^{2+}$ accumulated [ $\left.\mu \mathrm{mol}\right]$

$\square$ total $\mathrm{Ca}^{2+}$ accumulation time [min]

- $\mathrm{Ca}^{2+}$ accumulation rate $\left[\mu \mathrm{mol} \mathrm{min}^{-1} \mathrm{mg}\right.$ protein $\left.^{-1}\right]$

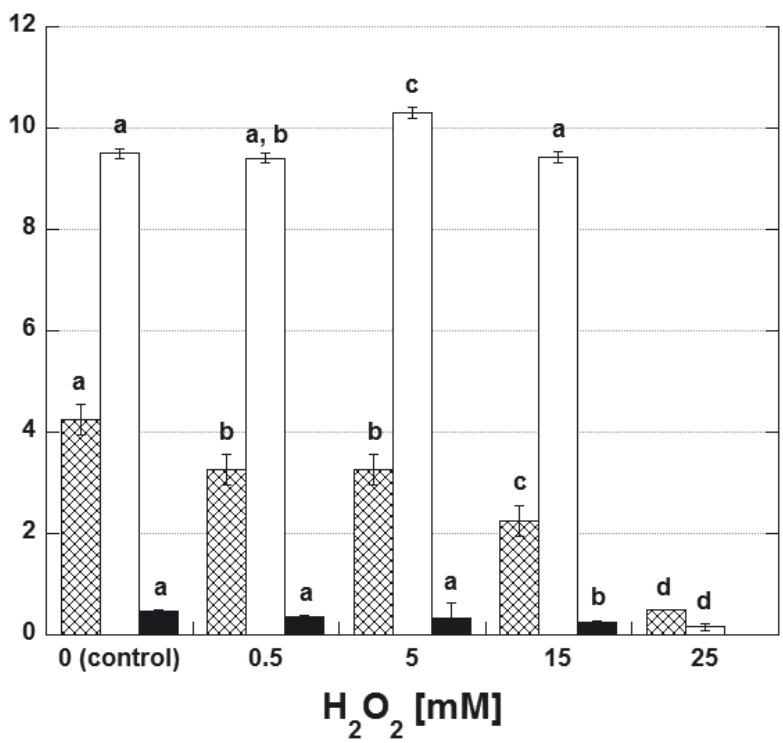

Figure 5. Calcium ion uptake by mitochondria of $A$. castellanii.

The amounts of $\mathrm{Ca}^{2+}$ accumulated by mitochondria of $A$. castellanii, estimated time of $A$. castellanii mitochondria over-accumulation and disruption, and $\mathrm{Ca}^{2+}$ accumulation rates are shown $( \pm$ S.E.). For each variant, means with different letters are significantly different (Tukey's HSD test, $P=0.05)$. P-values are based on one-way ANOVA.

measurements at $550 \mathrm{~nm}$ of supernatants of mitochondria incubated with $\mathrm{H}_{2} \mathrm{O}_{2}$ and $\mathrm{Fe}^{2+}$. For each measurement the same volume of supernatant was used. The absorbance values of released cytochrome $c$ shown in Fig. 6 were means of four independent measurements. Surprisingly, we did not observe a consistent increase of cytochrome $c$ release from mitochondria of $A$. castellanii subjected to increasing stress conditions. Instead, an increase was observed from the control to the $15 \mathrm{mM}$ treatments, and a slight decrease for the $25 \mathrm{mM}$ treatment compared to the $15 \mathrm{mM}$ treatment. This result may suggest that a heme group in cytochrome $c$ underwent peroxidation by the Fenton reagents and product during the incubation.

\section{DISCUSSION}

Reactive oxygen species are involved in cell damage and death. Intact cells that start to fail when oxidative stress occurs launch antioxidant defences to detoxify these harmful compounds (Radi et al., 1993; Lenaz et al., 1999; Fleury et al., 2002). However, ROS are not only dangerous molecules for the cell. They also display a physiological role as mediators

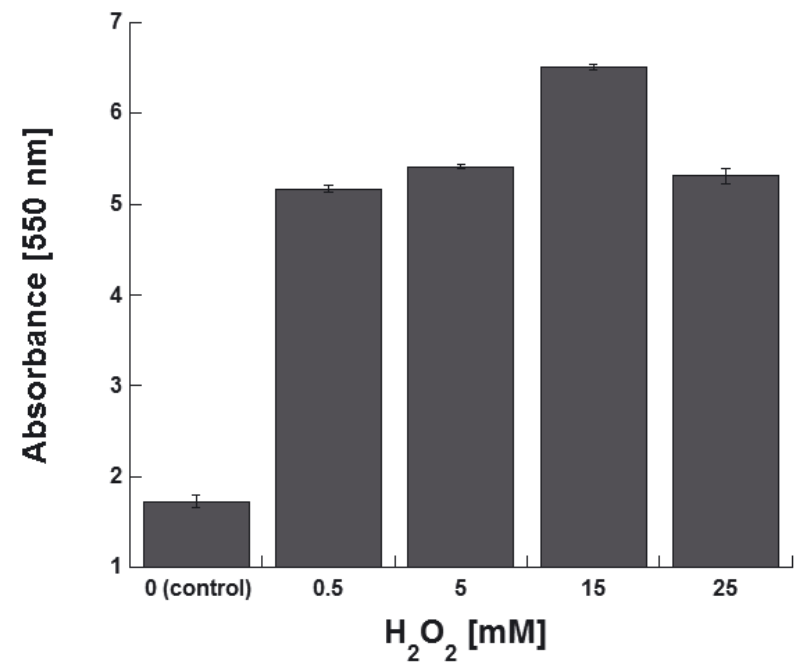

Figure 6. Release of cytochrome $c$ from A. castellanii mitochondria assessed spectrophotometrically at the wavelength of $550 \mathrm{~nm}( \pm$ S.E.).

in signal transduction pathways (Fleury et al., 2002). Hydrogen peroxide is a signalling molecule that controls a variety of stress responses and physiological adjustments in plants under stress conditions (Ślesak et al., 2007).

The results of our study revealed that the Fenton reaction (its reagents and product) triggers oxygen consumption increase, cytochrome $c$ release, membrane potential dissipation, and loss of $\mathrm{Ca}^{2+}$ ion accumulation in mitochondria of Acanthamoeba castellanii.

Two parameters, $\mathrm{RC}$ and $\mathrm{ADP} / \mathrm{O}$, informed us which mitochondrial component, respiratory chain complexes or ATP-synthase, may have been initially damaged by oxidative stress. Damage to ATP synthase caused RC to decrease as a consequence of non-effective protonmotive force and a decline in ATP synthesis. The respiratory chain was still able to build the protonmotive force but the process required extra time. In this case, the $\mathrm{ADP} / \mathrm{O}$ ratio for control and $0.5 \mathrm{mM}$ stress treatments did not change significantly (Fig. 3). At the same time, RC decreased significantly for the $0.5 \mathrm{mM}$ treatment in comparison with the control (Fig. 2). This occurred because the $\mathrm{ADP} / \mathrm{O}$ ratio depends on proton influx (through the respiratory chain pumps) and efflux (by ATP synthase) stoichiometry. When respiratory chain complexes are damaged, the $\mathrm{ADP} / \mathrm{O}$ ratio changes as a result of proton stoichiometry disruption.

Notably, our experiments demonstrate that $\mathrm{H}_{2} \mathrm{O}_{2}$ concentration as low as $0.5 \mathrm{mM}$ in the presence of $\mathrm{Fe}^{2+}$ contributes to disturbances in the generation of membrane potential (Fig. 4), transport of electrons through the respiratory chain, oxidative phosphorylation (not shown), and uptake and accumulation of $\mathrm{Ca}^{2+}$ (Fig. 5). The respiration rate coefficient de- 
creased by $32 \%$ after one minute of incubation with $0.5 \mathrm{mM} \mathrm{H}_{2} \mathrm{O}_{2}$ (Fig. 2), while the $\mathrm{ADP} / \mathrm{O}$ did not change significantly (Fig. 3). Under these conditions, $\mathrm{Ca}^{2+}$ active accumulation ability also decreased by 1000 nmols in comparison with the control (Fig. 5). Therefore, it is possible that even $0.5 \mathrm{mM} \mathrm{H}_{2} \mathrm{O}_{2}$ may, within a short time, break outer membrane integrity and/or ATP synthase complexes. In addition, this stress condition led to the release of cytochrome $c$ (Fig. 6), which is in agreement with results of prior studies (Minotti \& Aust, 1987; Kowaltowski et al., 1996; Kroemer et al., 1997; Martinou et al., 2000). The following increase of oxidative stress conditions contributed to the decrease both RC and ADP/O and ability to accumulate calcium ions (Figs. 2, 3, and 5, respectively). These effects may be a result of membrane peroxidation and, in consequence, membrane potential depletion and lack of the ability to accumulate $\mathrm{Ca}^{2+}$. Reactive oxygen species damaged respiratory chain complexes, which in turn disrupted proper $\mathrm{ADP} / \mathrm{O}$ stoichiometry.

Calcium ions are transported through the outer membrane by the voltage dependent anion selective channel (VDAC) that contains $\mathrm{Ca}^{2+}$-binding domains (Gincel et al., 2001) and/or by $\Delta \Psi_{\mathrm{m}}$-dependent $\mathrm{Ca}^{2+}$ uniporter located in the inner mitochondrial membrane (Bernardi, 1999). The results of our study suggest that the loss of the ability to accumulate $\mathrm{Ca}^{2+}$ is not a result of $\Delta \Psi_{\mathrm{m}}$ depletion alone. Reactive oxygen species may also damage both calcium pathway proteins (VDAC and $\mathrm{Ca}^{2+}$ uniporter). The intracellular $\mathrm{Ca}^{2+}$ concentration stimulates $\mathrm{Ca}^{2+}$ uniport channel activity. The $\mathrm{Ca}^{2+}$ uniporter contains a regulatory $\mathrm{Mg}^{2+}$-binding domain. Binding of $\mathrm{Mg}^{2+}$ by the $\mathrm{Ca}^{2+}$ uniporter influences the kinetics of $\mathrm{Ca}^{2+}$ ion flux, while $\mathrm{Mg}^{2+}$ are not channeled by the $\mathrm{Ca}^{2+}$ uniporter (Bernardi, 1999). The putative groups binding $\mathrm{Mg}^{2+}$ are sulphydryl groups of cysteine (Wudarczyk et al., 1999). Reactive oxygen species may decrease $\mathrm{Ca}^{2+}$ uniporter activity by oxidizing these sulphydryl groups and therefore reducing $\mathrm{Mg}^{2+}$ binding. Reactive oxygen species readily penetrate lipid bilayers and damage cell proteins. The question arising is: which channel system allows $\mathrm{Ca}^{2+}$ to get through the outer mitochondrial membrane and how do free radicals damage the channel system in A. castellanii? Previous studies show that VDAC contains $\mathrm{Ca}^{2+}$ binding domains in rat liver mitochondria (Gincel et al., 2001). They point to a paper concerning similar experiments conducted on Paramecium aurelia (Protista), in which VDAC did not display a $\mathrm{Ca}^{2+}$ affinity (Schein et al., 1976).

In higher plants, $\mathrm{H}_{2} \mathrm{O}_{2}$ molecules produced by mitochondria may play a secondary signal role by inducing $A O X$ gene(s) or other genes related to resistance mechanisms after respiratory chain damage. Vyssokikh and Brdiczka (2003) observed increased respiration and $A O X 1$ gene expression in the case of respiratory chain inhibition. In our study, we also noted increased respiration following increased oxidative stress conditions (Figs. 1a and b). Experiments on $A$. castellanii cells that show a higher AOX protein content during the logarithmic growth phase would be necessary to determine whether this alternative pathway actually raises the probability of survival under stress conditions (Purvis, 1997; Popov et al., 1997).

The lowest $\mathrm{H}_{2} \mathrm{O}_{2}$ concentration used in our study was 5-fold higher than that used for ferrous and hydrogen peroxide-dependent peroxidation of phospholipid liposomes (Minotti \& Aust, 1987). This suggests that mitochondria of $A$. castellanii contain an effective antioxidant-defence system for scavenging ROS and preventing damage. One of the system component might be a catalase, which occurs at a high concentration in A. castellanii mitochondria (Michejda et al., 1988). Another is alternative oxidase, which is also present in plant mitochondria. Czarna \& Jarmuszkiewicz (2005) proved that activation of AOX lowers ROS production in mitochondria of $A$. castellanii. The study used transgenic cultured tobacco cells with altered levels of AOX also indicated that the alternative pathway in plant mitochondria functions as a mechanism to decrease the formation of reactive oxygen species produced during respiratory electron transport (Maxwell et al., 1999). Sweetlove et al. (2002) demonstrated that treatment of Arabidopsis cell cultures with $88 \mathrm{mM} \mathrm{H}_{2} \mathrm{O}_{2}$ resulted in changes in isolated mitochondria. The authors observed a degradation of the tricarboxylic acid (TCA) cycle and respiratory chain proteins, and, contrary to our results, a decrease in respiration. Their results indicate that oxidative stress reduces the respiratory capacity primarily by inhibiting electron flow through respiratory dehydrogenases into the $\mathrm{Q}$ pool and by reducing the activity of the TCA cycle, rather than by affecting the activity of respiratory oxidases. The increase of oxygen consumption in our study may be due to an electron efflux via respiratory dehydrogenase into the $Q$ pool and interception by AOX molecules. Dissipation of membrane potential, $\mathrm{RC}$, and ADP/O suggest a loss of integrity of outer membrane that prevented conservation of the proton electrochemical gradient while increasing the consumption of oxygen.

Tiwari et al. (2002) observed faster oxygen consumption in mitochondria isolated from Arabidopsis cells treated with $1 \mathrm{mM}$ or $5 \mathrm{mM} \mathrm{H}_{2} \mathrm{O}_{2}$. However, the authors explained that the differences in electron transport were not associated with alternative oxidase activity because oxygen consumption was completely blocked by the addition of potassium cyanide.

In conclusion, this study allowed us to observe direct effects of reactive oxygen species on 
mitochondria of the soil protozoan Acanthamoeba castellanii. As low as $0.5 \mathrm{mM}$ concentration of $\mathrm{H}_{2} \mathrm{O}_{2}$ in the presence of $\mathrm{Fe}^{2+}$ damaged the energetics of mitochondria of $A$. castellanii. We observed increased respiration in state 3 and 4 , decrease of $\Delta \Psi_{\mathrm{m}^{\prime}}$ respiratory rate coefficient (RC), $\mathrm{ADP} / \mathrm{O}$ ratio, $\mathrm{Ca}^{2+}$ uptake, and an increased release of cytochrome $c$ in mitochondria of A. castellanii subjected to oxidative stress.

\section{Acknowledgements}

We are grateful to Dr. Lee E. Frelich (University of Minnesota, St. Paul, USA) for language correction of the manuscript.

\section{REFERENCES}

Balzacq AS, Vieira HLA, Kroemer G, Brenner C (2002) The adenine nucleotide translocator in apoptosis. Biochemie 84: 167-176.

Bernardi P (1999) Mitochondrial transport of cations: channels, exchangers and permeability transition. Physiol Rev 79: 1127-1155.

Chen Q, Vazquez EJ, Moghaddas S, Hoppel CL, Lesnefsky EJ (2003) Production of reactive oxygen species by mitochondria: Central role of complex III. J Biol Chem 278: 36027-36031.

Czarna M, Jarmuszkiewicz W (2005) Activation of alternative oxidase and uncoupling protein lowers hydrogen peroxide formation in amoeba Acanthamoeba castellanii mitochondria. FEBS Lett 579: 3136-3140.

Domka-Popek A, Michejda JW (1986) The upake of $\mathrm{Ca}^{2+}$ by mitochondria of amoeba supported by malate or ATP. Bull Soc Sci Lett 25.

Fleury C, Mignotte B, Vayssière JL (2002) Mitochondrial reactive oxygen species in cell death signaling. Biochimie 84: 131-141.

Garnier M, Dimchev A, Boujard N, Price J, Musto N, Papadopoulos V (1994) In vitro reconstitution of a functional benzodiazepine receptor from mouse Leyding tumor cells. Mol Pharmacol 45: 201-211.

Gincel D, Zaid H, Shoshan-Bermatz V (2001) Calcium binding and translocation by the voltage-dependent anion channel: a possible regulatory mechanism in mitochondrial function. Biochem J 358: 147-155.

Halestrap AP, McStay GP, Clarke SJ (2002) The permeability transition pore complex: another view. Biochemie $\mathbf{8 4}$ : 1153-1166.

Jarmuszkiewicz W, Wagner AM, Wagner JM, Hryniewiecka L (1997) Immunological identification of the alternative oxidase of Acanthamoeba castellanii mitochondria. FEBS Lett 411: 110-114.

Kowaltowski A, Castilho R, Verces A (1996) Opening of the mitochondrial transition pore by uncoupling or inorganic phosphate in the presence of $\mathrm{Ca}^{2+}$ is dependent on mitochondrial-generated reactive oxygen species. FEBS Lett 378: 150-152.

Kroemer G, Zamzani N, Susin SA (1997) Mitochondrial control of apoptosis. Immunol Today 18: 44-51.

Lenaz G, Bovina C, FormigginiG. Castelli-Parenti G (1999) Mitochondria, oxidative stress, and antioxidant defences. Acta Biochim Polon 46: 1-21.
Li Y, Trush MA (1998) Diphenyleneiodonium, an NAD(P)H oxidase inhibitor, also potently inhibits mitochondrial reactive oxygen species production. Biochem Biophys Res Commun 253: 295-299.

Martinou JC, Deshager S, Antonsson B (2000) Cytochrome $c$ release from mitochondria: all or nothing. Nature Cell Biol 2: E41-E43.

Maxwell DP, Wang Y, McIntosh L (1999) The alternative oxidase lowers mitochondrial reactive oxygen production in plant cells. Proc Natl Acad Sci USA 96: 82718276.

Michejda JW, Schöneich J, Hryniewiecka L (1988) Activity of catalase in Acanthamoeba castellanii grown in conditions preferring the activity of cytochrome or alternative respiratory pathways. Bull Soc Sci Lett 26.

Minotti G, Aust SD (1987) The requirement for iron (III) in the initiation of lipid peroxidation by iron (II) and hydrogen peroxide. J Biol Chem 262: 1098-1104.

Papa S, Skulachev VP (1997) Reactive oxygen species, mitochondria, apoptosis and aging. Mol Cell Biochem 174: 305-319.

Purvis AC (1997) Role of the alternative oxidase in limiting superoxide production by plant mitochondria. Physiol Plant 100: 165-170.

Radi R, Bush KM, Freeman BA (1993) The role of cytochrome $c$ and mitochondrial catalase in hydroperoxideinduced heart mitochondrial lipid peroxidation. Archiv Biochem Biophys 300: 409-415.

Schein SJ, Colombini M, Finkelstein A (1976) Reconstitution in planar lipid bilayers of a voltage-dependent anion-selective channel obtained from Paramecium mitochondria. J Membr Biol 30: 99-120.

Shimizu S, Narita M, Tsujimoto Y (1999) Bcl-2 family proteins regulate the release of apoptogenic cytochrome $c$ by the mitochondrial channel VDAC. Nature 399: 483487.

Shimizu S, Ide T, Yanagida T, Tsujimoto Y (2000) Electrophysiological study of novel large pore formed by Bax and the voltage-dependent anion channel that is permeable to cytochrome c. I Biol Chem 275: 12321-12325.

Stridh H, Kimland M, Jones DP, Orrenius S, Hampton MB (1998) Cytochrome $c$ release and caspase activation in hydrogen peroxide- and tributyltin-induced apoptosis. FEBS Lett 429: 351-355.

Sweetlove LJ, Heazlewood JL, Herald V, Holtzapffel R, Day DA, Leaver CJ, Millar AH (2002) The impact of oxidative stress on Arabidopsis mitochondria. Plant J 32: 891-904.

Ślesak I, Libik M, Karpińska B, Karpiński S, Miszalski Z (2007) The role of hydrogen peroxide in regulation of plant metabolism and cellular signalling in response to environmental stresses. Acta Biochim Polon 54: 39-50.

Tiwari BS, Belenghi B, Levine A (2002) Oxidative stress increased respiration and generation of reactive oxygen species, resulting in ATP depletion, opening of mitochondrial permeability transition, and programmed cell death. Plant Physiol 128: 1271-1281.

Vyssokikh M, Brdiczka D (2003) The function of complexes between the outer mitochondrial membrane pore (VDAC) and the adenine nucleotide translocase in regulation of energy metabolism and apoptosis. Acta Biochim Polon 50: 389-404.

Wudarczyk J, Dębska G, Lenartowicz E (1999) Zinc as inducer of the membrane permeability transition pore in rat liver mitochondria. Archiv Biochem Biophys 363: 1-8. 